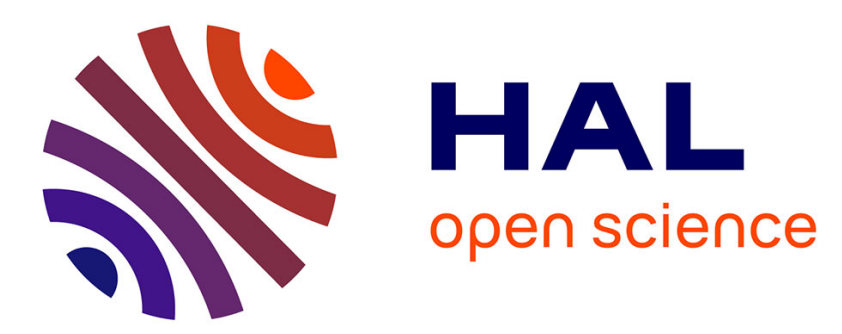

\title{
Transport phenomena in a cold wall vertical reactor for metalorganic vapor phase growth of $\beta$-SiC layers
}

H. Chehouani, S. Benet, B. Armas, C. Combescure, A. Figueras, S. Garelik

\section{To cite this version:}

H. Chehouani, S. Benet, B. Armas, C. Combescure, A. Figueras, et al.. Transport phenomena in a cold wall vertical reactor for metalorganic vapor phase growth of $\beta$-SiC layers. Journal de Physique IV Proceedings, 1993, 03 (C3), pp.C3-131-C3-138. 10.1051/jp4:1993316 . jpa-00251373

\section{HAL Id: jpa-00251373 https://hal.science/jpa-00251373}

Submitted on 1 Jan 1993

HAL is a multi-disciplinary open access archive for the deposit and dissemination of scientific research documents, whether they are published or not. The documents may come from teaching and research institutions in France or abroad, or from public or private research centers.
L'archive ouverte pluridisciplinaire HAL, est destinée au dépôt et à la diffusion de documents scientifiques de niveau recherche, publiés ou non, émanant des établissements d'enseignement et de recherche français ou étrangers, des laboratoires publics ou privés. 


\title{
Transport phenomena in a cold wall vertical reactor for metalorganic vapor phase growth of $\beta$-SiC layers
}

\author{
H. CHEHOUANI, S. BENET, B. ARMAS*, C. COMBESCURE* , A. FIGUERAS ${ }^{* *}$ and \\ S. GARELIK ${ }^{* *}$
}

LPA, Université de Perpignan, 66860 Perpignan, France

*IMP/CNRS, BP. 5, 66120 Odeillo, France

*** Institut de Ciencia de Materials de Barcelona, CSIC, Campus de la UAB, 08193 Cerdanyola, Spain

\begin{abstract}
The deposition rate and uniformity in CVD reactors are function of transport phenomena. A mathematical model including the coupled mass transfer with hydrodynamics and heat transfer has been developed to predict reactant concentrations, flow patterns and temperature fields in a cold wall CVD reactor. The model consists of the partial differential equations describing the balance of mass, momentum, heat and species concentration and variable gas properties. The equations are solved numerically in two-dimensional, axisymmetric form using a control-volume-based finite difference technique. The model is applied to growth of silicon carbide layers obtained by LPCVD from the pyrolysis of tetramethylsilane. We present computed temperature, velocity and TMS concentration profiles. We compare predicted deposition rates with experimental results
\end{abstract}

\section{1-INTRODUCTION}

The coating of materials for protection, hardness and resistance to wear find a large field of industrial applications. In this case, the coatings are obtained by chemical decomposition of raw vapours or gases. The substrate is helded at sufficient temperature for the growth of the layer. However, the coating properties are strongly linked with the operating conditions in the deposition run. Furthermore, the yield performance (e.g. deposition rate, film composition and uniformity) is related to the substrate temperature, total pressure, reactant concentrations, gas flow rate and geometry of the reactor which are the more important parameters to be controlled. The conventional approaches based to a large extent on intuition and step-by-step improvement are often used. These are time-consuming and expensive and their major inconvenience is their lack of generality. It is difficult to extend the results to different cases and especially to different reactor configurations. This becomes particularly crucial when one wants to transfer from laboratory study to industrial scale reactors. For this reason, both experimental and theoretical efforts of recent years have been aimed towards a more fundamental understanding of the relevant physicochemical mechanisms of the CVD technique [1-10]. In this way, the development of mathematical models based simultaneously on fluid dynamics, kinetics and thermodynamics has led to an enormous increase in the interpretation of diagnostic experiments.

Our purpose in this paper is to discuss the development of a mathematical model for a vertical cold wall LPCVD reactor for $\beta$-SiC growth layers. We describe in detail the model, including the set of governing partial equations and the numerical method used to solve the problem. A previous experimental study on the kinetics of $\beta$-silicon carbide deposition from TMS permits to take out the assumptions that we have based our theoretical model. We also present computed temperature velocity and chemical species concentration profiles. We compare predicted thickness and deposition rates with experimental in order to check the model validity. 


\section{2- EXPERIMENTAL}

Polycrystalline layers of $\beta$-SiC has been grown by LPCVD on graphite substrate by thermal decomposition of tetramethylsilane $\left(\mathrm{Si}\left(\mathrm{CH}_{3}\right)_{4}\right.$, TMS) using $\mathrm{H}_{2}$ as a carrier gas. The growth of $\beta$-Sic layers was studied as a function of deposition temperature. The TMS precursor was chosen because it supplies $\mathrm{Si}$ and $\mathrm{C}$ from individual molecule free from halogen.

A schematic of the cold wall LPCVD reactor is shown in figure 1. It consists of a vertical silica tube of $40 \mathrm{~mm}$ in diameter. A graphite substrate, with a radius of $8 \mathrm{~mm}$ and a thickness of $8 \mathrm{~mm}$ is placed in such a way that it is perpendicular to the flow of gases. It is heated with an induction coil of copper tube wound on the exterior wall of the reactor. The flow of gases of purity $99.99 \%$ are controlled by mass flowmeters. The TMS is maintained at $20^{\circ} \mathrm{C}$ to control its vapour pressure. The substrate temperature, $\mathrm{T}_{\mathrm{S}}$, is kept between 1100 and $1500^{\circ} \mathrm{C}$ and is measured by an optical pyrometer placed in the geometrical axis of the deposition system.

Kinetic study TMS pyrolysis were performed "in situ" by means an automatic microbalance. Weight variations produced by films deposition were studied as a function of the deposition time. Series of runs with various operating conditions have shown that the growth rate is a function of the pressure and the substrate temperature [10].

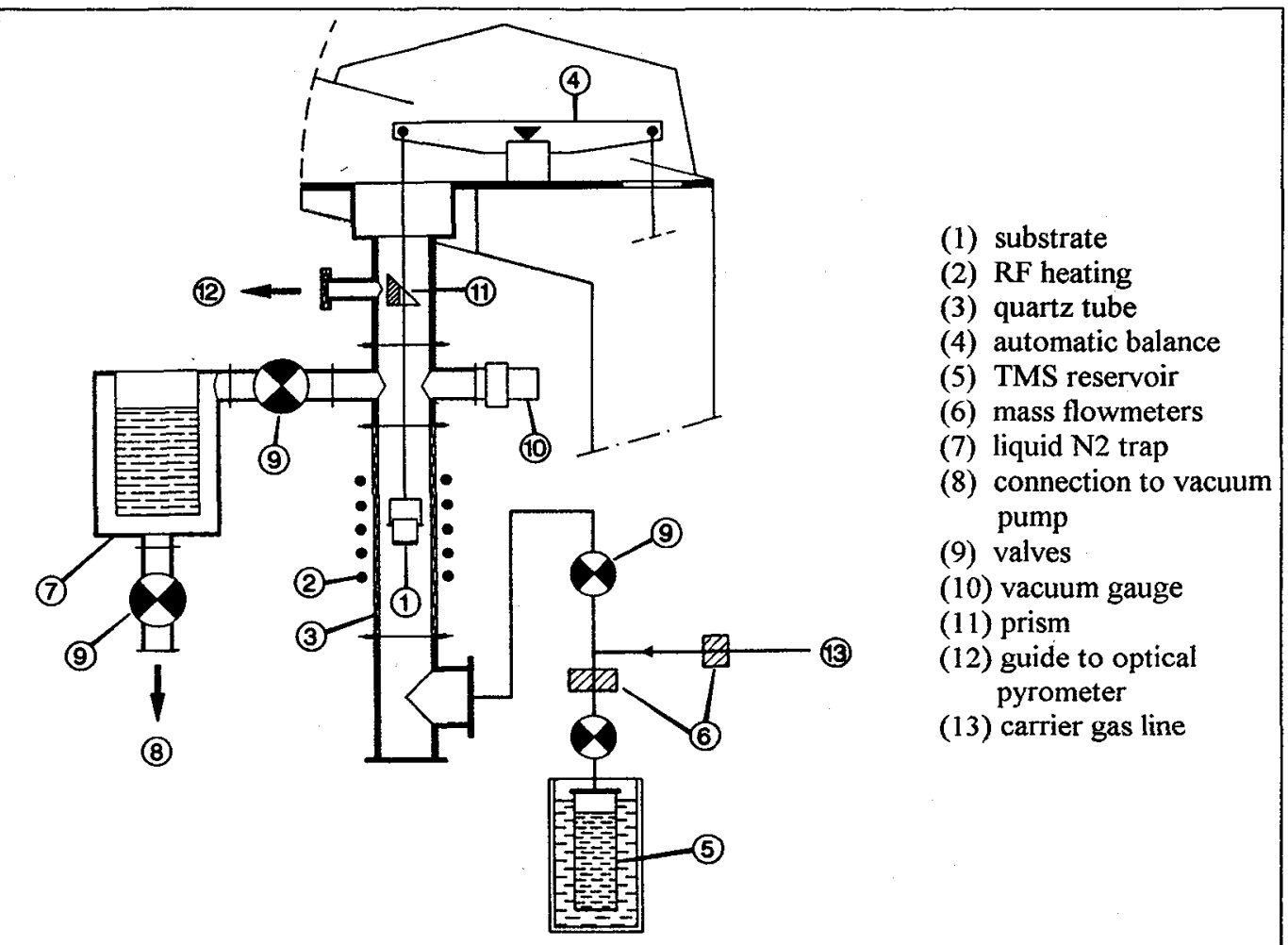

Figure 1 : Experimental arrangement used for the decomposition of TMS 


\section{3-MODEL FORMULATION}

A complete model of the behaviour of a CVD reactor is based upon the momentum, energy and species equations with appropriate boundary conditions, describing the gas flow, heat and mass transfer. The complexity of the CVD process arises from the fact that all these phenomena occur simultaneously and are strongly dependant upon one another. Fortunately, some simplifying assumptions will be used to reduce the numerical problem to reasonable size :

First, in experimental systems the reactives are often heavily diluted in a carrier gas. Hence, the flow and heat transfer can be decoupled from the mass transfer and consequently only this carrier gas $\left(\mathrm{H}_{2}\right)$ could be taken into account. With the removal of dependence of the flow on species balance, the problem becomes sequential instead of fully coupled. The temperature and velocity fields obtained in this way can be envisaged for modelling different chemical reactions.

Secondly, stationary laminar axisymmetric gas flow is assumed. Our experimental study of heat transfer in CVD reactors by holographic interferometry has shown that transition to turbulent motion depends strongly to the pressure, and gas flow rate [9]. For the low flow rates and total pressure encountered in LPCVD reactors no disturbance of the temperature field is expected.

Thirdly, the time dependent terms of the momentum, energy and species balance can be ignored. The film growth rate encountered in CVD process is rather slow compared to the gas phase dynamics. In fact, typical deposition rates are on the order of $10^{-8} \mathrm{~m} / \mathrm{s}$ and gas velocity are on the order of $1 \mathrm{~m} / \mathrm{s}$.

Basiquely with the three assumptions above the flow and heat transfer equations reduce to the following forms writen in terms of stream function and vorticity $(\Psi, \omega)$ :

$$
\left\{\begin{aligned}
& \text { Flow equations } \\
& \frac{\partial}{\partial \mathrm{r}}\left(\frac{1}{\rho \mathrm{r}} \frac{\partial \psi}{\partial \mathrm{r}}\right)+\frac{\partial}{\partial \mathrm{z}}\left(\frac{1}{\rho \mathrm{r}} \frac{\partial \psi}{\partial \mathrm{z}}\right)=-\omega \\
& \frac{\partial}{\partial \mathrm{r}}\left(-\frac{1}{\mathrm{r}} \frac{\partial \psi}{\partial \mathrm{z}} \omega\right)+\frac{\partial}{\partial \mathrm{z}}\left(\frac{1}{\mathrm{r}} \frac{\partial \psi}{\partial \mathrm{r}} \omega\right)=\frac{1}{\operatorname{Re}}\left\{\frac{\partial}{\partial \mathrm{r}}\left[\frac{1}{\mathrm{r}} \frac{\partial}{\partial \mathrm{r}}(\mu \mathrm{r} \omega)\right]+\frac{\partial^{2}}{\partial \mathrm{z}^{2}}(\mu \omega)\right\}+\frac{1}{\mathrm{Fr}} \frac{\partial \rho}{\partial \mathrm{r}} \\
&+\frac{\partial \rho}{\partial \mathrm{r}} \frac{\partial}{\partial \mathrm{z}}\left(\frac{\mathrm{V}_{\mathrm{r}}^{2}+\mathrm{V}_{\mathrm{z}}^{2}}{2}\right)-\frac{\partial \rho}{\partial \mathrm{z}} \frac{\partial}{\partial \mathrm{r}}\left(\frac{\mathrm{V}_{\mathrm{r}}^{2}+\mathrm{V}_{\mathrm{z}}^{2}}{2}\right)
\end{aligned}\right.
$$

Heat transfer equation

$$
\mathrm{C}_{\mathrm{p}}\left(-\frac{1}{\mathrm{r}} \frac{\partial \psi}{\partial \mathrm{z}} \frac{\partial \Theta}{\partial \mathrm{r}}\right)+\frac{\partial}{\partial \mathrm{z}}\left(\frac{1}{\mathrm{r}} \frac{\partial \psi}{\partial \mathrm{r}} \frac{\partial \Theta}{\partial \mathrm{z}}\right)=\frac{1}{\operatorname{Re} \operatorname{Pr}}\left[\frac{1}{\mathrm{r}} \frac{\partial}{\partial \mathrm{r}}\left(\mathrm{r} \lambda \frac{\partial \Theta}{\partial \mathrm{r}}\right)+\frac{\partial}{\partial \mathrm{z}}\left(\lambda \frac{\partial \Theta}{\partial \mathrm{z}}\right)\right]
$$

Where we define the stream function and the vorticity by the following relations :

$$
\mathrm{V}_{\mathrm{r}}=-\frac{1}{\rho \mathrm{r}} \frac{\partial \psi}{\partial \mathrm{z}} \quad ; \quad \mathrm{V}_{\mathrm{z}}=\frac{1}{\operatorname{\rho r}} \frac{\partial \psi}{\partial \mathrm{r}} \quad ; \quad \omega=\frac{\partial \mathrm{V}_{\mathrm{r}}}{\partial \mathrm{z}}-\frac{\partial \mathrm{V}_{\mathrm{z}}}{\partial \mathrm{r}}
$$

In these equations, variables have been made dimensionless by scaling them with a reference value which is here chosen at the inlet reactor. The resulting dimensionless numbers are defined as below : 
Reynolds number $\operatorname{Re}=\frac{\mathrm{V}_{0} R_{0} \rho_{0}}{\mu_{0}} ;$ Froude number $\mathrm{Fr}=\frac{\mathrm{V}_{0}^{2}}{\mathrm{gR}_{0}} \quad ; \quad$ Prandtl number $\operatorname{Pr}=\frac{\mu_{0} C_{\mathrm{p}}}{\lambda_{0}}$

In these expressions, $\rho_{0}, \mu_{0}, \lambda_{0}, C_{P}$ and $V_{0}$ are respectively the gas properties and the mean velocity at the reactor inlet. $R_{0}$ is the reactor radius and $\mathrm{g}$ is the acceleration due to gravity. Since the flows are all low Mach number, incompressibility assumption is adopted. In the energy equation the contribution of Dufour effects, viscous dissipation, radiation, and the heat generated by reaction are ingored. With the velocities and temperature obtained from the equations above, the species balance can be solved to yield the concentration fields. When neglecting gas phase reactions and taking into account the dilution assumption which allows the substitution of the more simple FICK's law of species diffusion for the Stefan-Maxwell equations, the mass balance for the species is :

$$
C\left(V_{r} \frac{\partial X_{i}}{\partial r}+V_{z} \frac{\partial X_{i}}{\partial z}\right)=\frac{1}{\operatorname{Re~Sc}_{i}}\left[\frac{1}{r} \frac{\partial}{\partial r}\left(C_{i, c g} r \frac{\partial X_{i}}{\partial r}\right)+\frac{\partial}{\partial z}\left(C D_{i, c g} \frac{\partial X_{i}}{\partial z}\right)\right]
$$

where the subscripts " $\mathrm{i}$ " and "cg" denote TMS and carrier gas $\mathrm{H}_{2}$ respectively, $\mathrm{C}$ is the dimensionless total concentration of $\mathrm{H}_{2}\left(=\mathrm{T}_{0} / \mathrm{T}\right), X_{\mathrm{i}}$ is the mole fraction of TMS in the carrier gas. $D_{\mathrm{i}, \mathrm{cg}}$ is the dimensionless diffusion coefficient of TMS in $\mathrm{H}_{2}$ and $\mathrm{Sc}_{\mathrm{i}}$ is the Schmidt number of TMS defined as $\mu_{0}\left(\rho_{0} D_{i, c g}\right)^{-1}$

In the above equations, several thermophysical properties appear, which are a function of temperature and pressure. Their values could be obtained, when available, from experimental data or established from stastical mechanical theory [11]. In this way viscosity $\mu$, thermal conductivity $\lambda$ and binary diffusion coefficient $D_{i, c g}$ can be fitted in a power law dependence facilitating numerical calculations as given in table 1. The heat capacity $\mathrm{Cp}$ per unit mass is assumed to be constant. The ideal gas law is used to compute the density as a function of temperature.

Table 1 Fitting relation for the transport properties of $\mathrm{H}_{2}$ and TMS $\mathrm{T}_{0}=293 \mathrm{~K}, \mathrm{P}_{0}=1.013 \times 10^{5} \mathrm{~Pa}$

\begin{tabular}{|c|c|}
\hline $\begin{array}{c}\text { Thermal conductivity } \\
\lambda\left(\mathrm{W} \cdot \mathrm{m}^{-1} \cdot \mathrm{K}^{-1}\right)\end{array}$ & $2 \times 10^{-2}\left(\frac{\mathrm{T}}{\mathrm{T}_{0}}\right)^{0.6838}$ \\
\hline $\begin{array}{c}\text { Viscosity } \\
\mu\left(\mathrm{kg} \cdot \mathrm{m}^{-1} \cdot \mathrm{s}^{-1}\right)\end{array}$ & $0,1797 \times 10^{-4}\left(\frac{\mathrm{T}}{\mathrm{T}_{0}}\right)^{0.6841}$ \\
\hline $\begin{array}{c}\text { Heat capacity } \\
\mathrm{C}_{\mathrm{p}}\left(\mathrm{J} \cdot \mathrm{kg}^{-1} \cdot \mathrm{K}^{-1}\right)\end{array}$ & 1043 \\
\hline $\begin{array}{c}\text { Density } \\
\rho\left(\mathrm{kg}^{-3}\right)\end{array}$ & $\frac{\mathrm{PM}}{\mathrm{RT}}$ \\
\hline $\begin{array}{c}\text { Binary diffusion coefficient } \\
\mathrm{D}_{\text {i.cg }}\left(\mathrm{m}^{2} \cdot \mathrm{s}^{-1}\right)\end{array}$ & $2,26 \times 10^{-5}\left(\frac{\mathrm{P}_{0}}{\mathrm{P}}\right)\left(\frac{\mathrm{T}}{\mathrm{T}_{0}}\right)^{1.5}$ \\
\hline
\end{tabular}

To make the above set of equations a well-posed problem, appropriate boundary conditions must be specified for velocity components, the temperature and the species concentrations. The reactor is assumed to be axisymmetric so no variations or velocity components in the angular direction. No slip at the walls and substrate, uniaxial flow at the inlet, no radial gradient at the centreline and no axial gradient at the outlet are assumed for the flow boundary conditions. In other hand, the walls and substrate are assumed to be isothermal. The concentration boundary conditions are : uniform mole fraction $X_{i}$ of TMS at the reactor inlet, no net flux at all nonreactive boundaries (centreline, walls, and outlet). At the 


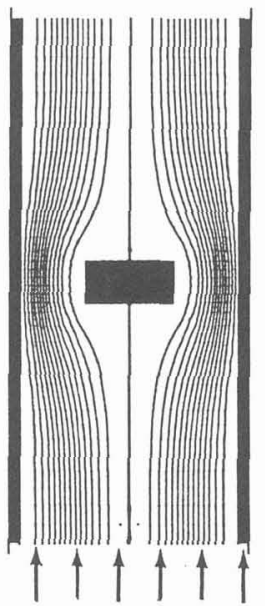

Figure 2: calculated streamlines in the reactor

Figure 4 : isotherms in the reactor from $100^{\circ} \mathrm{C}$ to $1400^{\circ} \mathrm{C}$, step $100^{\circ} \mathrm{C}$
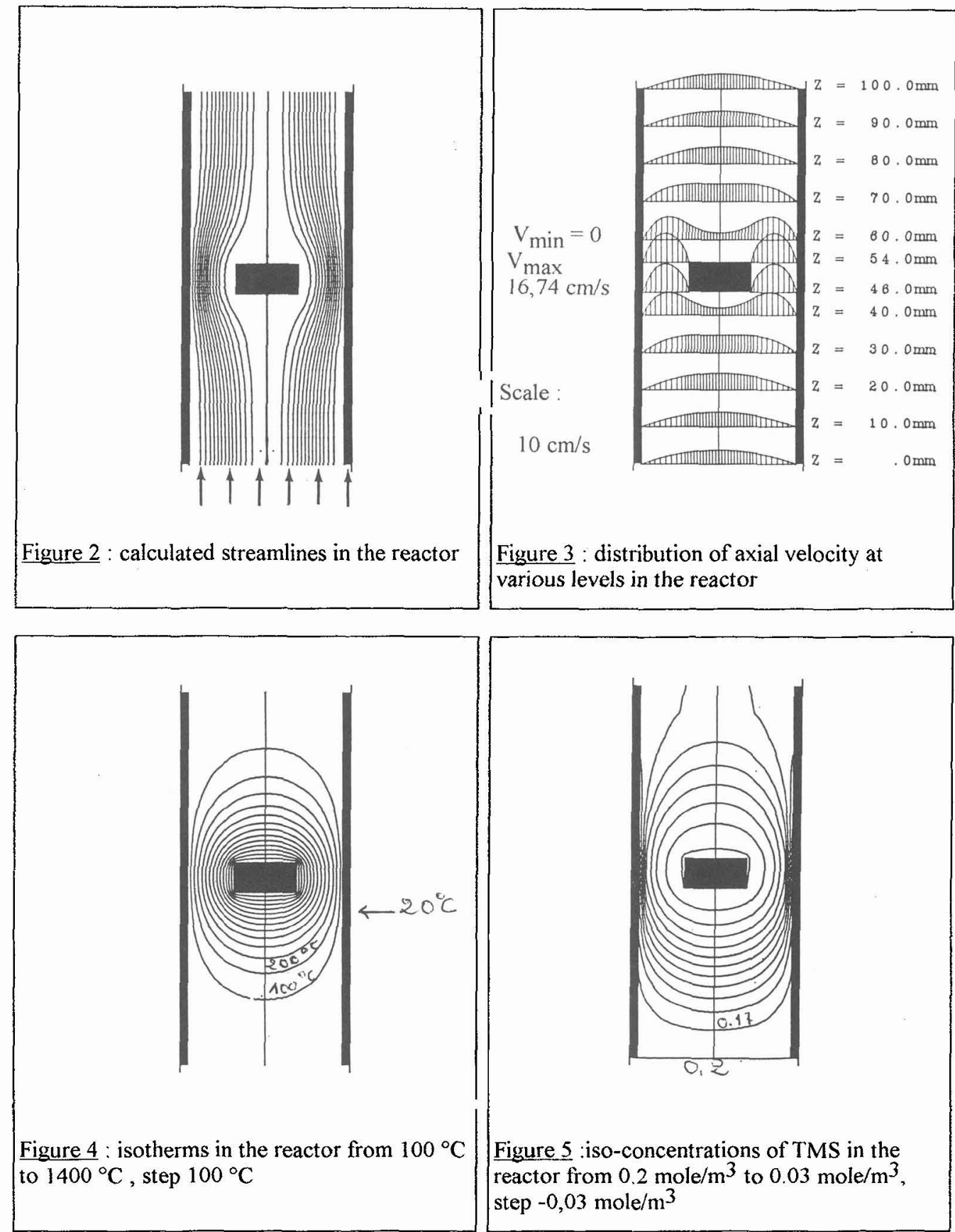

Figure 5 :iso-concentrations of TMS in the reactor from $0.2 \mathrm{~mole} / \mathrm{m}^{3}$ to $0.03 \mathrm{~mole} / \mathrm{m}^{3}$ step $-0,03 \mathrm{~mole} / \mathrm{m}^{3}$ 
substrate surface, we assume that the deposition $\mathrm{SiC}$ take place following an heterogeneous reaction in the form:

$$
\mathrm{Si}\left(\mathrm{CH}_{3}\right)_{4} \quad \rightarrow \quad \mathrm{SiC}+3 \mathrm{CH}_{4}
$$

Moreover, we assume that the substrate temperature, pressure are chosen in a manner that the mass transfer is the limited regime. In this case, the flux of TMS is equal to the first order reaction rate thus :

$$
-C D_{i, c g} \frac{\partial X_{i}}{\partial n}=k_{\text {surf }} \cdot C_{i, s u r f}
$$

where $\partial / \partial \mathrm{n}$ is the derivative along the outward normal to the substrate surface, $\mathrm{k}_{\text {surf }}$ is the first order rate constant and $\mathrm{C}_{\mathrm{i} \text {,surf }}$ is the concentration of TMS on the surface.

\section{4- NUMERICAL SOLUTION}

The equations ( 1 to 4 )in the mathematical model are of the convection-diffusion type and could be written in the general form given by Gosman [12]. This common formulation has many practical advantages since it provides to use one numerical algorithm to solve all equations. The computational domain is discretized into a number of adjoining non-uniform grid cells each of them surrounding one grid point in which the solution field $\left(\Psi, \omega, \Theta, X_{i}\right)$ is to be found. It consists of 1071 grid nodes in total in the radial and axial directions is solved using a control volume-based finite differences method [9,12]. The general equation is integrated over the surface element surrounding each point of the mesh. Because of the non-linearity of the equations and the complexity of the terms to be integrated, a linear approximation of the dependant variables $\left(\Psi, \omega, \Theta, X_{i}\right)$ was necessary to facilitate the integration of the equation. The sets of algebraic equations resulting from the numerical scheme were solved iteratively using a Gauss-Seidel method. The iteration procedure was terminated when the convergence criterion :

$\left|\frac{\varphi^{n}-\varphi^{n-1}}{\varphi_{\max }^{n-1}}\right| \leq 5.10^{-4}$ with $\varphi=\psi, \omega, \Theta$, or $X_{i}$ and $n=$ iteration number

was fulfilled at any node. To reach this criterion, 300-500 iterations were needed, taking 10-20 min of CPU time. All calculations were carried out on a NORSK-DATA ND 5700 minicomputer.

\section{5-RESULTS}

\section{5-1 The flow and isotherms}

Figure 2 shows the flow patterns in the reactor computed for the TMS/H2 system under classical LPCVD conditions $\left(\mathrm{Q}_{\mathrm{H}_{2}}=100 \mathrm{scm}^{3} / \mathrm{min}, \mathrm{Q}_{\mathrm{TMS}}=15 \mathrm{scm}^{3} / \mathrm{min}, \mathrm{P}=4 \mathrm{kPa}\right)$. The temperatures of the wall and the subsrate are respectively $\mathrm{T}_{\mathrm{S}}=1673^{\circ} \mathrm{C}$ and $\mathrm{T}_{0}=20^{\circ} \mathrm{C}$. Expressed in the dimensionless numbers we have $\operatorname{Re}=0.27, \mathrm{Fr}=0,66 \times 10^{-2}$ and $\mathrm{Pr}=0,7$. We note the absence of the buoyancy and inertial recirculating flows which are unfavoured by low pressure and total gas flow rate. At this low Reynolds number, the flow becomes a creeping flow thus the streamlines follows the form of the substrate. In the annular zone between the substrate and the reactor wall, the flow is approximately axial one with an increase velocity and narrower streamlines which is illustrated in figure 3 showing the distribution of axial velocity at various levels in the reactor.

Figure 4 shows the predicted isotherms in the reactor Here again we clearly observe the absence of gravity effects. At low pressures and gas flow rates, diffusive heat transfer prevail the free-convective and 


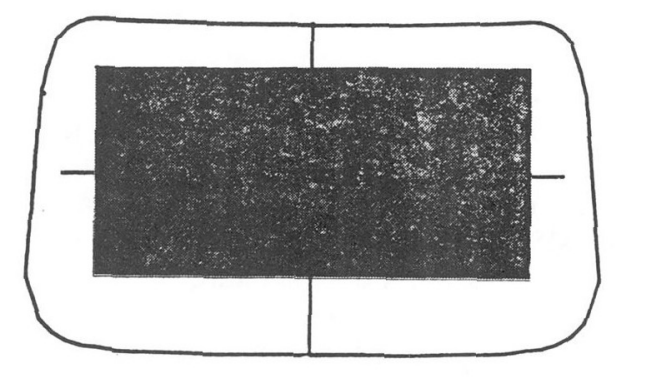

Figure 6 : calculated $\mathrm{SiC}$ deposition profile

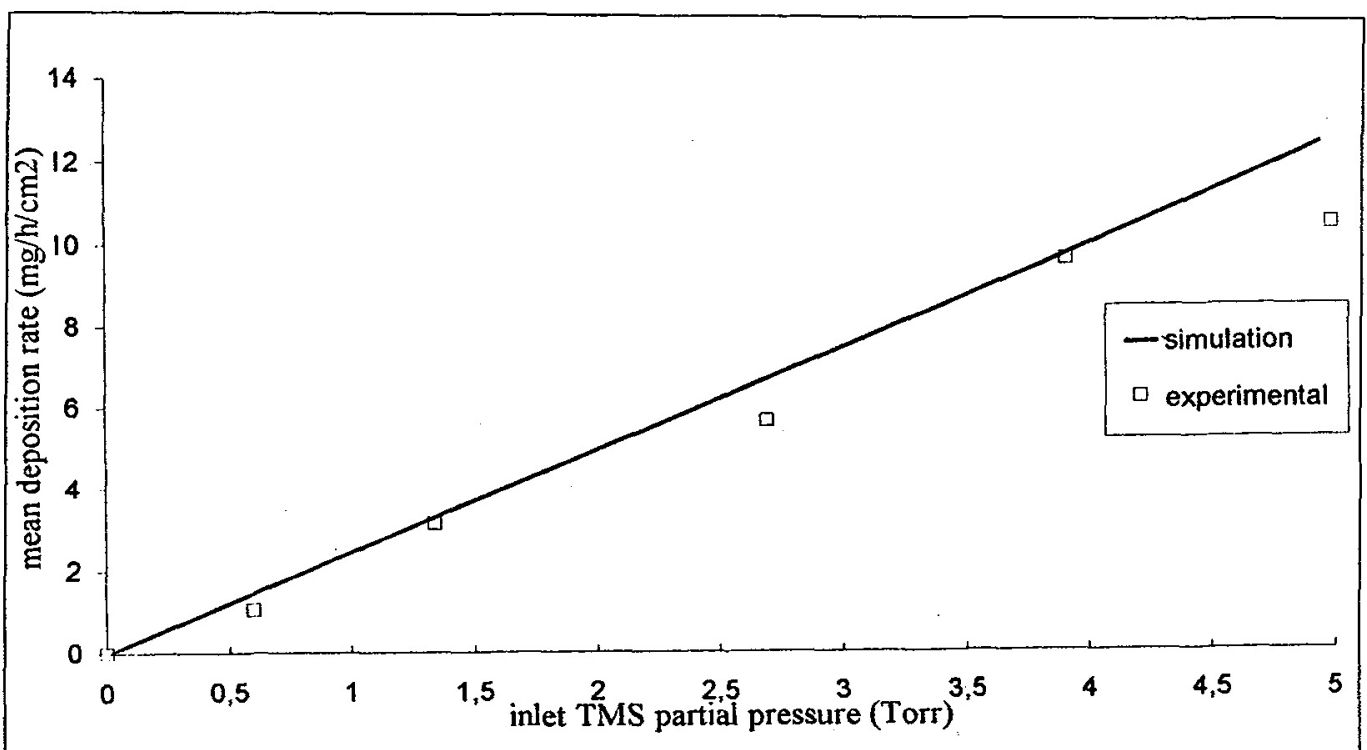

Figure 7 : variation of the mean deposition rate with the inlet TMS partial pressure 
forced-convective transport processes in the reactor and causes the temperature gradients in the upper part and lower part of the reactor to be similar [9].

\section{5-2 Concentration distribution and deposition rate profile}

Figure 5 illustrates the TMS concentration distributions in the reactor for $\mathrm{QH}_{2}=100 \mathrm{scm} / \mathrm{min}$, $Q_{\mathrm{TMS}}=15 \mathrm{scm}^{3} / \mathrm{min}, \mathrm{P}=4 \mathrm{kPa}$ and $\mathrm{k}_{\text {Surf }}=0.044 \mathrm{~m} / \mathrm{s}$ Thus the Shmidt number (which is the ratio between momentum diffusivity and species diffusivity) is $\mathrm{Sc}=9,6$. When the mass transfer is the limiting step of the kinetic process, the concentration of TMS decreases as the gaseous phase is flowing up in the reactor. This depletion of TMS reactant along the reactor causes the deposit thickness on the substrate surface to be rather heterogeneous as illustrated in figure 6 . This simulation shows that ratio between the deposit thicknesses respectively on the lower and the upper surface of the substrate is approximatively 2 . This result is in accordance with the experimental observations. Moreover, in order to check the validity of the mathematical model we have calculated the mean deposition rates over the entire substrate surface for several inlet TMS partial pressure and compared the result to the coresponding experimental data as shown in figure 7. We can note a small deviation between the experience and the simulation which predects higher deposition rate at high inlet TMS partial pressures

\section{6-CONCLUSION}

The presented mathematical model of growth of silicon carbide layers obtained by LPCVD from the pyrolysis of tetramethylsilane within a cold wall reactor provides a complete description of the transport processes. The results shows the influence of the coupled flow and heat transfer on the species transport and thereby on the deposit layer thickness on the substrate. Qualitatively the model predictions of the deposition thickness profile is in good agreement with experimental observations. Quantitatively the computed deposition rates present a slight deviation from the experimental data. Therefore this result could be improved by making some refinement of the described model. This could be achieved by taking into acount the coupling between the flow, heat and mass transfer and adding the thermal diffusion effect in the TMS concentration equation.

\section{REFERENCES}

[1] COCHET G, MELLOTTEE H, DELBOURGO R, J. Electrochem. Soc. 125, N³, (1978) p 487

[2] WAHL G, HOFFMANN R, Rev. int. Htes Temp.\& Refrac., Fr. 17 (1980) p 7

[3] GRANIER B, ARMAS B, BENET S, Proc of the sixth European Conf. on C.V.D. Edited by R.Porat (1987) p 1

[4] VINANTE C, DUVERNEUIL P, COUDERC J.P, J. Phys. Colloque C5, Supplément No 5, Tome $50,(1989)$ p 35

[5] KLEIJN C.R, VAN DER MEER Th.H, HOOGENDOORN C.J, J. Electrochem. Soc., N¹1, 136 (1989) p 3423

[6] FOTIADIS I, KIEDA S, JENSEN K.F, J.Crystal Growth N$^{\circ} 102$ (1990) p 441

[7] HOUTMAN C, GRAVES D.B, JENSEN K.F, J.Electrochem. Soc. 133, (1986) p 961

[8] LANGLAIS F, PREBENDE C, TARRIDE B, NASLAIN R, J. de Phys., Colloque C5, Supplément $\mathrm{N}^{\circ} 5$, Tome 50, (1989) 93

[9] CHEHOUANI H, Thèse de doctorat Université de Perpignan, $\mathrm{N}^{\circ} 101 \mathrm{C},(1990)$

[10] FIGUERAS A., GARELIK S., RODRIGUEZ-CLEMENTE R., ARMAS B., COMBESCURE C., DUPUY C, J. of Cristal Growth 110 (1991) pp 528-542

[11] HIRSCHFELDER J.O., CURTISS C.F., BIRD R.B., "Molecular Theory of Gases and Liquids", John Wiley and Sons Inc., New York, USA (1967)

[12] GOSMAN A.D, PUN W.M, RUNCHAL A.K, SPALDING D.B, WOLFSHTEIN M,

"Heat and mass Transfer in Recirculating flows" Academic Press, London, (1973) 